Review

\title{
The Gender Digital Divide in Developing Countries
}

\section{Amy Antonio ${ }^{1, *}$ and David Tuffley ${ }^{2}$}

1 Australian Digital Futures Institute, University of Southern Queensland, Education City, Sinnathamby Boulevard Springfield Central, Brisbane, QLD 4300, Australia

2 School of Information and Communication Technology, Griffith University, 170 Kessels Road Nathan, Brisbane, QLD 411, Australia; E-Mail: d.tuffley@griffith.edu.au

* Author to whom correspondence should be addressed; E-Mail: Amy.Antonio@usq.edu.au; Tel.: +61-439-469-495.

External Editor: Roderick Graham

Received: 2 September 2014; in revised form: 16 October 2014 / Accepted: 21 October 2014 / Published: 31 October 2014

\begin{abstract}
Empirical studies clearly show that women in the developing world have significantly lower technology participation rates than men; a result of entrenched socio-cultural attitudes about the role of women in society. However, as studies are beginning to show, when those women are able to engage with Internet technology, a wide range of personal, family and community benefits become possible. The key to these benefits is on-line education, the access to which sets up a positive feedback loop. This review gives an overview of the digital divide, before focusing specifically on the challenges women in developing countries face in accessing the Internet. Current gender disparities in Internet use will be outlined and the barriers that potentially hinder women's access and participation in the online world will be considered. We will then look at the potential opportunities for women's participation in a global digital society along with a consideration of current initiatives that have been developed to mitigate gender inequity in developing countries. We will also consider a promising avenue for future research.
\end{abstract}

Keywords: gender digital divide; digital literacy; education; developing countries 


\section{Introduction}

According to Curtis Kularski [1] (p. 5) "the digital divide is composed of a skill gap and a gap of physical access to Information Technology (IT) and the two gaps often contribute to each other in circular causation. Without access to technology, it is difficult to develop technical skill and it is redundant to have access to technology without first having the skill to utilise it".

Kularski's quote sums up the reiterative nature of the problem. More than two decades ago, apparent inequalities in Internet access gave rise to "concern that the new technology might exacerbate inequality rather than ameliorate it", which resulted in analysts focusing on what has been called the digital divide between the online and the offline [1] (p. 359). The digital divide is often conceptualised as the gap between those who have access to vital Information and Communication Technology (ICT) resources and those who do not [2]. Pippa Norris [3] described the digital divide as shorthand for any and every disparity within the online community, including access between developed and developing nations, the rich and poor, and men and women within those nations. She further describes the digital divide as a democratic divide between those who do and do not use the panoply of digital resources to engage, mobilise and participate in public life.

Norris's definition, which differentiates ICT access on the basis of "haves" and "have-nots", has evolved and the digital divide has become a complex phenomenon that can be understood in a myriad of ways. Van Dijk and Hacker [4] discuss the idea that access to digital resources is a multi-faceted phenomenon consisting of four factors that work to regulate access; psychological, material, skills and usage. What began as a simple concept of there being "haves" and "have-nots" in the digital world, has evolved into a finer-grain conceptual framework. Psychological access is where the user has little interest in gaining access, or has negative attitudes towards computers. Material access relates to not having the physical infrastructure. Skills access is where a person does not have the digital literacy skills to be effective on-line and usage access is where a person does not have the time or opportunity to access digital information, regardless of their skill level. The 4A perspective - awareness, access, attitudes and applications - focuses on digital gaps at the local/community level in addition to the national/global level, while the access-use definitions highlight the socio-economic factors, such as income and gender, that influence a person's ability to access ICT [5]. The knowledge gap hypothesis similarly posits that people of high socio-economic status are at an advantage because they find out about new sources of information first and because they can afford access to them while they are new [2]. Purpose definitions, on the other hand, consider variables such as autonomy of use, social support and reasons for using the Internet [5].

In each of these definitions, the digital divide is enacted in one of two ways: through lack of technical skill and/or through a physical limitation on access [1]. The term "access" in regards to the digital divide was initially used to refer to whether or not a person could connect to the Internet. Access later became a synonym for "use", at which time opportunity and choice were, unfortunately, conflated, as studies have since shown that more people have access to the Internet than actually use it [2]. The majority of existing research on the digital divide has focused on inequality of access. Although this is important because it is likely to reinforce other inequalities, such as opportunities for economic mobility and social participation, a more thorough understanding of digital inequality is required that looks at the Internet in its broader theoretical context and considers how ICT's impact on existing social inequalities [2]. 
An exploration of how access to ICTs perpetuate or reinforce gender inequality in developing countries is one such example. In this case a developing, or less developed, country is a nation with a lower living standard and a low Human Development Index (HDI) relative to other countries [6]. In contrast to developed or industrial nations, where women's Internet access and usage often exceeds that of men's, there is a prevailing gender digital divide in developing countries that warrants further exploration.

At the core of the digital revolution is the question of access to digital networks and, in particular, who gets empowered and who is informationally marginalised by the use of these new tools [7]. Digital technologies could, potentially, enable women to overcome longstanding inequalities by providing employment opportunities and chances to increase income, in addition to access to cost effective health care and education. On the flip side, it has been argued that women are at a natural disadvantage because they are, purportedly, less tech savvy, more technophobic and the technology itself has not been designed to meet their needs [7]. Although the definition of the gender digital divide remains deficit-focused, it has been tempered over the past decade with an acknowledgement that the divide is not simply an issue of access, but also of obstacles to Internet use [8]. That is, as ICTs diffuse widely across the world it becomes less useful to look merely at the binary classifications of ICT "haves" and "have nots" because the provision of physical ICT products does not guarantee that individuals will have the necessary skills to enjoy the benefits brought by ICTs [9].

\section{Social Inequalities Faced by Women}

The large majority of women (an estimated four out five [7]) live in developing countries and they often suffer even more gender-related discrimination than their counterparts in developed countries; they are more likely to be unemployed and have fewer employment and educational opportunities [10], with large numbers (approximately 60\% according to UN statistics [5]) ending up as unpaid family workers. These women are trapped in traditional family roles and lack the basic digital literacy skills that could allow them to achieve more of their potential [11].

Role definition underlies many of the reasons why women do not make ample use of technology. In Southern India, according to Vinitha Johnson [12] a woman's existence is defined as a source of support for her family and the wellbeing of the family unit. Culture, the media and society define the roles of women and they are not generally encouraged to fulfil their individual needs, or pursue self-growth, even in educated families. Similarly, in Ghana, there is strong correlation between an individual's work environment and access to digital resources. "While such access may seem gender neutral at face value, traditional gender roles, institutional structures and economic realities force disproportionate numbers of females into the informal sector where such opportunities for access are limited" [13].

The percentage of women using the Internet lags behind the percentage of men using the Internet in developing countries across all age groups. However, highly educated women are a notable exception, as they reportedly use the Internet as much as men, suggesting that given an education and the means to do so, women will make just as much use of the Internet as men, refuting the assertion that it is lack of capacity that causes women to otherwise not use the Internet. Researchers who attempted to measure the gender digital divide in six francophone countries in West Arica (Benin, Burkina, Faso, Cameroon, Mali, Mauritania, and Senegal) found no gender gap in connectivity or usage among young women educated to secondary school level and beyond [14]. This seems to indicate that education is a powerful tool in 
combating the gender gap in Internet access and use [15]. However, it is well documented that women face challenges in gaining access to education at all ages because of a lack of time to attend school, familial and household duties and socio-cultural norms that give a low priority to education [16]. As such, without careful planning, it is likely that ICTs will exacerbate differences between men and women as diffusion and use of ICTs and their benefits tend to follow existing contours of income and economic divides, with the poor being further marginalised or excluded [17].

In this review, we gathered existing literature to address the following questions: (i) To what extent do women in developing countries access the online world; (ii) What factors impede and facilitate Internet access; (iii) What are the potential benefits to women in developing countries of being online; and (iv) What can reduce inequalities and facilitate Internet access for women in developing countries?

\section{Methodology}

For this review, a literature search was undertaken by using the terms "gender digital divide", "digital literacy", "developing countries" and key phrases, such as "differences between women and men in ICT usage" and "gender differences in Internet access in developing countries". Of particular use in the search was the Intel "Women and the Web" report and the World Bank paper: "Information and Communication Technologies for Women's Socioeconomic Empowerment”. "Google Scholar" was also used to identify key resources. Many of the reports and briefing papers located in this manner yielded further results upon examination of not only the references used, but by following citations. In this way, the authors were able to follow the development of the key arguments in this field and identify the arguments with the highest impact. It is worth noting that, very little empirical research has been undertaken in the area of the gender digital divide and, as such, this review was reliant on Government reports and statistical data made available through various organisation, such as the United Nations, World Bank and Intel. Moreover, the initiatives outlined in this review are drawn predominantly from online newspapers and interviews with the founders of various organisations that have been established to address the gender digital divide. These proposed solutions, while appearing to empower women, have not been tested empirically to determine whether or not they are improving women's access to ICTs in developing countries. More research is still needed in this space.

\section{Internet Access for Women in Developing Countries}

ICTs have become an irreplaceable tool in society. The number of people going online to conduct everyday activities, such as business and banking, education, seeking employment, civic engagement and forming and maintaining social relationships, is increasing every day. For many of us, being digitally connected is an integral part of our day-to-day lives and it is difficult to imagine having to function without Internet access. For certain groups of people, such as women in developing countries, the Internet has real potential to mitigate or even remove the barriers that have precluded them from participating more fully in digital society. However, although their lower starting point provides for greater possible gains, these women continue to face gender-related discrimination that prevents them from accessing the full benefits of ICTs [7].

Few statistics on gender and ICT are available because many governments do not collect ICT statistics and rarely are they disaggregated by sex. Observational and anecdotal evidence [14] have identified a 
gender component to the digital divide in developing countries, but there is little data to document it. In 2005, the Digital Opportunity Index was introduced with the aim of tracking the progress made in bridging the digital divide. The DOI was built on three themes-opportunity, infrastructure and utilisation - which are not gender specific. The DOI does not collect sex-disaggregated statistics; its stated aim is to assess infrastructure according to household data, which assumes equal access for all members of a household, thereby ignoring some of the fundamental constraints to ICT access and use for many women [18]. As such, although it is evident that a gender digital divide exists in developing countries, it is difficult to know exactly how many women are accessing the Internet due to the failure of existing research to distinguish between opportunity of access and actual use of the Internet; socio-cultural factors are not taken into account.

According to Moolman, Primo and Shackleton [19] the gender digital divide is one of the most significant inequalities amplified by the digital revolution. Of the few studies that have sought to address Internet use specifically, most have found that women in developing countries are significantly less likely to use the Internet than men. Women are estimated to constitute $25 \%$ or less of Internet users in Africa, 22\% in Asia, 38\% in Latin America, and a mere 6\% in the Middle East [20]. Less than 10\% of Internet users in Guinea and Djibouti are women, less than $20 \%$ in Nepal and less than $25 \%$ in India. Only $20 \%$ of Internet users in Greece are women and slightly more than $25 \%$ in Portugal [14]. In Africa (where the gender digital divide is thought to be the widest), in 11 of the 13 countries, more men than women use the Internet. In one of the most technologically advanced countries, Kenya, 21\% of men and $11 \%$ of women (in the population sample used for this study) had used the Internet in August 2008. African women are also less literate: In Kenya, $77.2 \%$ of men compared to $68 \%$ of women. Fewer women are actively working or studying - $81.4 \%$ of Kenyan men and $49.9 \%$ of women - and women generally have less income. While $29.8 \%$ of Kenyan men belong to the top $25 \%$ income group of the country, only. $6 \%$ of women do. Controlling for these three variables (literacy, actively working or studying and belonging to the top income group) the gender digital divide disappears in most African countries. The results of this study suggest that the discrimination women face in many aspects of social life - employment, literacy and income — replicate the inequalities in ICT usage [7]. Similar results have been observed in developed countries also. In a study by Ono and Zavodny [9], a strong correlation was observed between digital inequalities in computer and Internet use and pre-existing inequalities. A higher GEM score (which indicates more gender equality), for example, is negatively associated with a gender gap in computer use and, inversely, gender inequality at the societal level is closely associated with a gender gap in computer use at home. This suggests that "pre-existing measures of economic and social inequality are reasonable predictors of inequality in IT usage" [9] (p. 1147).

In a recent study undertaken by Intel [21], in which 2200 women and girls from India, Egypt, Mexico and Uganda took part, it was found that $25 \%$ of women in developing nations lacked Internet access and this figure was as high as $45 \%$ in Sub-Saharan Africa. The report highlights the stubborn gap in women's access to the Internet in Africa, but also in the Middle East and other developing parts of the world. According to Elizabeth Weingarten [22], there are two critical factors that influence whether or not women can access the Internet: availability and affordability. As such, one of the recommendations outlined in the Intel report was for policymakers and technology companies to make the Internet more accessible and affordable on mobile phones [23]. It is estimated that, in developing nations, an Internet connection can cost up to $40 \%$ of annual per capita income, compared to just $1.7 \%$ of per capita Gross 
Net Income in wealthier nations. Weingarten notes that, while these barriers apply to both genders, they hinder women more than men because other cultural obstacles compound the problem. Internet cafes, for example, are an easy way to access the Internet but they are often impractical for women who cannot leave home for religious and cultural reasons [22], and/or because they are intimidating for women due to low technological expertise and their belief that they are socially unwelcome [24].

Although there appears to be problems in disaggregating sex-specific information regarding access and use of the Internet in developing nations, men undoubtedly have greater access to the Internet than women. However, given that Internet access exceeds Internet use by women in developing countries, more research is required to identify the barriers women face to taking advantage of the online world.

\section{Barriers to Internet Access for Women in Developing Countries}

In the developing world, it appears that the majority of women are not accessing the Internet to the same degree as men and, even when access to a computer and the Internet is available, women are not necessarily using it. We will now consider some of the barriers that have been implicated in the reduced access and use that women in developing countries have experienced. Gil et al. [25] identify four barriers that hinder women's access to and use of ICTs: Exclusion from technology education and design; limited free time; social norms favouring men; and financial and/or institutional constraints. Existing research on the gender digital divide invariably fits within these categories, which are thus used as the basis for analysis in this review.

\subsection{Exclusion from Technology Education and Design}

Melhem, Morrell and Tandon [17] claim that "women and girls are poorly placed to benefit from the knowledge society because they have less access to scientific and technical education specifically and to education in general". Access to education continues to be a greater barrier for women than men and it is estimated that two-thirds of the world's illiterate population are women. In contrast, across all developing countries, $75 \%$ of women are literate compared to $86 \%$ of men. In some countries, India for example, $51 \%$ of women can read and write compared to $75 \%$ of men and without this fundamental skill, the Internet and the benefits of the online world will remain out of reach [26].

Overcoming Internet access barriers requires action on a number of fronts. In order to reduce inequality in Internet access, we need to educate and train people to facilitate access and modify attitudes that may serve to impede access [10]. The Women and the Web report [26] revealed that one in five women in India and Egypt believe that the Internet is not appropriate for them, or that their families would disapprove, and that engaging online would not be beneficial regardless. These attitudes are presumably derived from their socio-cultural conditioning. $40 \%$ of women in this study, moreover, cited a lack of familiarity or comfort with technology as a reason for not pursuing Internet use and, typically, women who were uncomfortable with technology lacked the exposure to Internet technologies that would allow them to develop their computer and digital literacy skills.

In addition, it has been reported that one of the consequences of having relatively few women web developers and programmers is a lack of content relevant to women's needs and interests. Moreover, 90\% of online content is in English, yet only one-third of users worldwide speak it [5], which may create barriers to access for non-English speakers [27], many of whom are women living in rural and remote 
areas [17]. Furthermore, the content associated with new technologies, and terrestrial media generally, is largely male-centric. In 2010, the Global Media Monitoring Project (GMMP) [28] reported that only $12 \%$ of all news stories across the world's media focus specifically on women. The GMMP further noted that $46 \%$ of news stories reinforce gender stereotypes while just $6 \%$ challenge them. It is therefore unlikely that women in developing countries will be motivated to seek information online if the content is inaccessible (not available in their native languages) and irrelevant for their needs.

\subsection{Limited Free Time}

Women invariably bear a disproportionately heavy burden of household and family responsibilities. Due to the combination of domestic chores and their role as primary caretakers, women have very little free time to experiment with new technologies. They are further constrained by social norms that confer control of technology to men [20]. A major digital divide based on gender is emerging in India, which is partly attributed to the constraints that women face in accessing education due to a lack of time to attend school, familial and household duties and socio-cultural norms that give a low priority to education [16]. Moreover, the extent to which women exercise autonomy in using the web significantly influences the extent to which they can access it. There are several factors that contribute to a woman's autonomy. Location of access, for example, is important. If Internet access is only available outside the home, and the user has to travel long distances to an Internet-enabled facility, this is likely to reduce one's likelihood of pursuing the online environment. If access is available within the home, to what extent is women's autonomy limited by the actions of other family members? The greater the autonomy of use, the greater the benefits the user is likely to derive [9].

\subsection{Social Norms Favouring Men}

Technologies are often considered to be within the purview of men and gender norms about men's control of technology, information and knowledge limit women's opportunity to learn, use and benefit from technology [20]. More than two-thirds of the world's population still lack access to the Internet. Given that women enjoy fewer educational and career opportunities globally and, in some places, they face having to endure restrictive gender norms, it is not surprising that most of them are women [26]. As a result, conservative gender roles become even more entrenched due to a lack of exposure to alternative perspectives and women become increasingly marginalised as social connections are increasingly fostered and maintained online [26]. Even in countries where access is no longer an issue, "inequalities in actual use can hamper women's opportunities on both economic and social fronts. Access is necessary, but not sufficient, to close the gender digital divide" [14] (p. 36). Given the rapid proliferation of ICTs, most individuals are likely to have access; however, high rates of access do not imply high rates of usage and, as such, "the discourse on the digital divide has expanded to include a consideration of other factors that generate digital inequality" [15].

Ono and Zavodny [9] found that differences in IT usage along demographic and socioeconomic dimensions reflect the extent of differences in other areas of the economy and society. At the individual level "differentiated spread of the Internet (may) lead to increasing inequalities, befitting those who are already in advantageous positions and denying access to better resources for the underprivileged" [29] (pp. 826-827). That is, having Internet access does not necessarily imply use and DiMaggio et al. [2], 
among others, advocate the need to examine access and use separately so as to distinguish between opportunity and choice. "Use presumes access but not vice versa" [9] (p. 1137). Even in the developed nations that are the subject of this study, non-users are disproportionately female, older, less educated and poor, and similar patterns have been observed in developing nations. In terms of women non-users, we need to ask whether this is a choice that is freely made without constraints or whether this choice is influenced by larger social factors. Someone who has not completed high school, for example, may not be aware of what information is available online or how to navigate it. Simply giving such a person a computer and/or Internet access would not guarantee use and the results of this study certainly bear out this contention: computer ownership and use was positively associated with education in all five countries. Moreover, women are significantly less likely to use a computer at home, given ownership, which suggests that living in a household where a computer is available does not necessarily mean that women will use it; access does not translate to use in many cases.

There is further evidence that perceived benefit is another factor that influences women's use of ICTs in developing countries. Regardless of whether or not Internet access is available, women are less likely to use ICTs if they perceive the benefits of doing so to be low. However, Ono and Zavodny [9] (p. 1141) note that "both actual and perceived benefits of IT use may be related to larger social forces that are tied in with inequality at the macroeconomic and societal level". Melhem et al. [17] (p. 22) similarly assert that "social and cultural factors limit women's access to shared ICT facilities, such as tele-centres, which tend to become meeting places for young men, and hence deter women's absorption and adoption of ICTs to access information and knowledge". Furthermore, common access points such as tele-centres are often not open for women and, in several cultures, women's use of such facilities and their interaction with men in public locations is frowned upon [17]. Moreover, research [30] indicates that tele-centres in Sri Lanka have been less than successful due to a combination of factors, including cost, logistics, scarcity of resources, connectivity speeds and lack of support.

\subsection{Financial and/or Institutional Constraints}

Chadwick et al. [10] (p. 380) note that, "due to its role as a means of information gathering and sharing, use of ICT corresponds to having increased power and control within society. The digital divide draws attention to how disempowered groups with limited economic resources have reduced access to ICTs". There are still 1.4 billion people living on less than US\$1.25 a day, and at least $70 \%$ of them are in rural areas [20]. Moreover, women often do not control finances or have sufficient personal income to purchase products or pay Internet service providers for monthly access [17]. As such, due to financial and institutional barriers, women lack the means to use, rent or purchase established and new technologies that could help them advance economically. The combination of laws, policies and social customs in many developing countries prohibit women from owning property and obtaining loans for technology purchases. A vicious cycle is thus perpetuated in which "women cannot develop their skills, which prevents them from earning higher incomes, so they cannot afford the technologies that might boost them to the next rung on the economic ladder" [20] (p. 7).

To summarise, there appear to be a number of barriers that prevent women in developing countries from accessing and using the Internet: "For many women, ICTs remain inaccessible due to affordability issues associated with poverty, lack of basic technological skills, low levels of literacy and numeracy, 
geographic isolation, and poor technology infrastructure...as well as the cultural expectations, norms and mores that influence the ability of women to own and/or access ICTs in public places" [18] (p. 135). The reason why fewer women access and use ICTs is a direct result of their unfavourable conditions with respect to education, employment and income. When these variables are controlled, women are generally more active users of digital technologies than men [31].

\section{Potential Benefits of Internet Use and Initiatives to Reduce the Digital Gender Divide}

Access to the Internet can provide a wealth of opportunities for women in developing countries, opening up avenues for learning, communication, generating income and business pursuits. According to Chadwick et al. [10] (p. 384) "government initiatives to address the digital divide may be necessary to ensure that this often economically under-privileged group are able to get online and receive the full benefits of digital inclusion". A number of positive initiatives have commenced to address impairments to Internet access and use by women in developing countries and these are considered below.

\subsection{Online Social Relationships and Identity Expression}

In terms of communication, women can benefit from faster and cheaper communication, which can facilitate and strengthen relationships among family, friends and business related social networks. Unfortunately, mobile phones have also been a source of conflict between spouses, which may have the inadvertent effect of reinforcing traditional gender power differentials. There have been anecdotal accounts of husbands dictating women's use of mobile phones and reports of mistrust and jealousy that have resulted in physical and verbal abuse. As such, "new technologies can become another aspect of oppression of women by men and a source of inequality between them" [17] (p. 34).

However, one possible mechanism of empowerment for women in developing countries is social networking sites, which encourage and facilitate self-expression. They also allow women to communicate with others beyond their geographical location and enhance their understanding of how the rest of the world works, which allows them to contextualise their own position within it and reflect on it critically. By forming connections on social media, women learn about the possibilities open to them, fostering a sense that they can change their current situation [26]. For example, earlier this year, a woman in Iran posted a scarf-less picture of herself on Facebook accompanied by the hashtag: \#mystealthyfreedom. Her actions sparked an online revolution, with over 230,000 people supporting her crusade of bareheaded subversion. The overwhelming response she received suggests that Iranian women are unhappy with the government's demand that they cover up and they are looking for a means to express themselves and voice their opposition to the compulsory hijab [32].

Having support to go online may help women in developing countries address the negative stereotypes and attitudinal biases that may impede access. Conservative gender roles invariably become reinforced when there is a lack of exposure to alternative perspectives. In 2007, the Feminist Approach to Technology (FAT) project was founded in New Delhi, India, with the aim of increasing women's technical awareness. This initiative addresses one of the biggest hurdles women face in Internet use and access: cultural stigma. This program has helped girls realise that it is possible to go to college and get scholarships [26]. The Internet also allows women to reduce the stigma they experience and give voice to their own concerns, whilst retaining a degree of anonymity. The Women's Net Digital Stories project 
equips women with the skills to tell their own stories. The storytellers participate in a workshop in which they make a short move about their lives. One of the participants recently shared her experience as a survivor of domestic violence and, by speaking out about violence again women, an opportunity to counter oppression by men is created. In South Africa, radio is, for many, the most common source of information. However, at the level of programming, very little content is aimed at women's information needs. The (S)he bytes project thus works with community radio stations to promote localised content that addresses women's concerns [19].

\subsection{Economic Opportunities}

Women's use of ICTs could, potentially, play a part in sustainable rural poverty reduction. Women play a crucial role in food production and distribution. Given access to price and product information, supply chain options for exporters and knowledge that helps improve their earnings and competitive power will result in increased wealth and economic development. Evidence suggests that women's economic advancement promotes overall economic growth. Studies from Cameroon and Kenya [33] have shown that increasing women's control over household inputs and farm income could boost farm yields by as much as $20 \%$. Simulations from Latin America [34] likewise indicate that the elimination of occupational and usage discrimination against women could lead to a $9 \%$ increase in Gross Domestic Product (GDP) and a World Bank [33] study found that Indian states with higher female labour market participation rates enjoyed greater poverty reduction. These studies suggest that "access to information and knowledge in rural areas has a significant impact on women's social and political participation and women's economic empowerment as agricultural producers. Women can use ICTs and the Internet to access the agri-business supply chain and promote their products for better sales" [17] (p. 28).

In addition to participation in the agricultural sector, there are a number of examples of mothers, disadvantaged and single women using ICTs to actively participate in the knowledge economy. For home-based women, ICTs can, potentially, allow them to find livelihoods that increase their productivity and family income. For example, the members of the eHomeakers grassroot community and the Mothers for Mothers network in Malaysia have successfully pursued tele-exchange and tele-trading careers from home. Moreover, for women juggling family and career, this could mean being able to work from home and fulfil multiple roles of homemaker and co-provider [18]. Moreover, the combination of untapped markets and weak local content offerings has provided a commercial avenue for women to develop knowledge and resources to serve women, their families and communities in ways the male-dominated field has not yet considered [17]. In 2010, a woman co-founded the website SuperMama in Egypt, which offers tools and information in Arabic for new mothers in the Middle East. It is hoped that as women adopt these tailored sites, they will encourage their friends to log on, which will expand the number of new female users and technology entrepreneurs [22]. More female entrepreneurs - and more women who use the Internet simply to find work - means poor communities will be better off: According to one study, women reinvest $90 \%$ of their income back into the family [23].

Technology gives women many opportunities for economic advancement. However, without the skills to use the technologies, women can remain on the lowest levels of the economic ladder. As such, a number of initiatives have been introduced to educate women and girls in the use of ICTs. To address women's under-representation in highly-skilled ICT occupations, CISCO systems launched a training 
initiative to provide women with the skills to use ICTs. The Achieving E-Quality in the IT sector initiative trained women at universities in Egypt, Jordan and Lebanon to design, build and maintain computer networks and other ICT applications. This program gives women a competitive edge in the high-skilled labour force [34]. In addition to teaching basic literacy skills, the Women's Annex Foundation [31] has also included Bitcoin (a software based online payment system) literacy in their training. The young women and children enrolled in these programs learn digital literacy skills and crypto currency in parallel. Fereshteh Forough, one of the co-founders of Women's Annex, acknowledges the importance for women of managing and controlling their own money: "Once all Afghans make a digital wallet and start paying their bills and shop online, then everybody will be treated equally in this digital financial world". At the Women's Annex Foundation, women who produce great content, in the form of articles and blogs, get paid in Bitcoin, based on the quality of their work, which they use to help support their families [35].

\subsection{Education and Training Initiatives}

With regards to increased life opportunities for women in developing countries, the Internet can reduce physical barriers to education and learning by allowing women to receive long-distance education via the Internet, particularly with the rise of high quality, free courses in a wide range of disciplines - the MOOC phenomena (Massively Open Online Course). It is not enough to simply have access to ICTs. It is equally important that women have the knowledge and resources to translate access into effective use. ICT initiatives will only be effective if the information is useful and relevant to the end user and where the end-users have the capacity to act on it [19]. Intel recognises the vital role technology plays in both improving the quality of and access to education. Through access to technology, scholarship and community learning programs, Intel provides girls and women with opportunities for quality education and personal growth [36]. In 2012, Intel joined with various organisations to improve education systems across the Asia Pacific. The Easy Steps Program is a digital literacy program for learners with little or no prior computer experience. The program has been implemented in the Philippines and its reach expanded through social media, namely a Filipino Facebook page. This online content has since been translated and implemented in other Asia Pacific countries. The Easy Steps Program focuses specifically on instruction for women and includes skills training in running Internet searches, using email and word processors for creating resumes and other documents, and creating spreadsheets to manage business and personal finances. The program facilitates the development of digital literacy skills and, more importantly, allows women to immediately apply these skills in their personal or professional lives [37].

In 2013, following the release of the "Women and the Web" report, Intel announced the She Will Connect [36] program - a new initiative to reduce the gender and technical gap around the world. The aim of the program is to expand digital literacy skills to young women in developing countries. The initiative commenced in Africa, where the gender gap is greatest, with a goal to reach five million women and so reduce the gender gap by $50 \%$. The long-term aim of the She Will Connect Project is to double the number of women and girls in developing countries from 600 million to 1.2 billion in three years. Similarly, the Telecentre Women: Digital Literacy Campaign is a global initiative to empower women with knowledge of ICTs for their personal growth. The program has provided digital literacy 
training to over one million women, which increases her value in the family and the wider community. The Telecentre woman becomes more employable, is able to contribute more and is an asset to any enterprise [18]. Digital literacy training for women is a common theme in these solutions to bridge the gender digital divide. The Women's Annex Foundation [31] was established to empower women in Central Asia by building access to the Internet and developing women's digital literacy skills. This foundation had expanded and now includes digital literacy training for women and children in 245 countries so that they can create a sustainable economic model for themselves and their families.

\section{Conclusions}

It is becoming increasingly clear from the various initiatives in developing countries around the world that women have the capacity, and in many cases the desire, to engage more fully with ICTs, yet for a range of socio-cultural reasons, for example traditional ideas of the place of women in society being domestic, women are being denied or are denying themselves access to technologies. The consequences of not having at least equal participation rates as men with Internet technologies are significant at both a personal and community level. If an otherwise capable woman is prevented from progressing beyond the traditional roles of child-rearing and housekeeping, she is unlikely to reach her full potential as a human being. At the community level and beyond, the impact of such women being unable to participate in economic activities will have a dampening effect on the often-struggling economies of these developing countries.

There is strong evidence to suggest that education is a solution. A woman who is educated to at least secondary level acquires both the ability and the desire to engage with the possibilities that Internet technologies offer, whereas a woman who is uneducated is more likely to subscribe to the traditional role of women and not engage with technology, regardless of their access to it. The increasing availability of high quality and often free education on-line is likely to improve this situation in a positive feedback loop. The more women engage with technology, the better educated they become and the more likely they will be to engage in activities that benefit themselves, their families, and their communities. They will then be more likely to undertake more of the kind of education that leads to improved living standards and a host of other benefits.

Working against the trend towards greater technology participation by women in developing countries are the deeply entrenched societal roles of women being primarily concerned with child-rearing and housekeeping. Any changes that occur will have to take place despite neutralising reactions within these societies that work to maintain the status quo. For future study, there is a clear need for research to be done to more fully understand the socio-cultural factors that both inhibit and encourage the engagement of women with technology. This understanding would be useful in devising strategies that incrementally improve the situation over time. This slow-paced approach may seem counter-intuitive, given the need, but arguably when dealing with age-old cultural practices, the slow and steady approach is more likely to succeed and produce long-term benefits than any effort at revolutionary change can produce.

\section{Author Contributions}

Both Amy Antonio and David Tuffley contributed equally to this article. Amy Antonio developed the conceptual framework for the review and wrote the initial draft. David Tuffley conducted a critical 
review of the article and contributed material pertaining to the education of women in developing countries. Both authors were responsible for editing the manuscript for final submission.

\section{Conflicts of Interest}

The authors declare no conflict of interest.

\section{References}

1. Kularski, C.; Moller, S. The digital divide as a continuation of traditional systems of inequality. Sociology 2012, 5151, 1-23.

2. DiMaggio, P.; Hargittai, E.; Celeste, C.; Shafer, S. Digital inequality: From unequal access to differentiated use. In Social Inequality; Neckerman, K.M., Ed.; Russell Sage Foundation: New York, NY, USA, 2004; pp. 355-400.

3. Norris, P. Digital Divide: Civic Engagement, Information Poverty, and the Internet Worldwide (Communication, Society and Politics); Cambridge University Press: Cambridge, MA, USA, 2001.

4. Van Dijk, J.; Hacker, K. The digital divide as a complex and dynamic phenomenon. Inf. Soc. Int. J. 2003, 19, 315-326.

5. Unites Nations (UN) e-Government Survey 2012. Available online: http://unpan3.un.org/egovkb/ Portals/egovkb/Documents/un/2012-Survey/unpan048065.pdf (accessed on 12 July 2014).

6. Library of Congress Collections Policy Statements. 2008. Available online: http://www.loc.gov/ acq/devpol/devcountry.pdf (accessed on 11 July 2014).

7. Hilbert, M. Digital gender divide or technologically empowered women in developing countries? A typical case of lies, damned lies and statistics. Women's Stud. Int. Forum 2011, 34, 479-489.

8. Kennedy, T.; Wellman, B.; Klement, K. Gendering the digital divide. Inf. Technol. Soc. 2003, 1, 72-96.

9. Ono, H.; Zavodny, M. Digital inequality: A five country comparison using microdata. Soc. Sci. Res. 2007, 36, 1135-1155.

10. Chadwick, D.; Wesson, C.; Fullwood, C. Internet access by people with intellectual disabilities: Inequalities and opportunities. Future Internet 2013, 5, 376-397.

11. Telecentre Women: Digital Literacy Campaign 2012. Available online: http://women.telecentre.org (accessed on 7 July 2014).

12. Johnson, V. The gender divide: Attitudinal issues inhibiting access. In Globalization, Technology Diffusion, and Gender Disparity: Social Impacts of ICTs; Pande, R., van der Weide, T., Eds.; IGI Global: Hershey, PA, USA, 2012; pp. 110-119.

13. Kwami, J. ICT4D, gender divides and development: The case of Ghana. In Development Communication in Directed Social Change: A Reappraisal of Theory and Practice, 1st ed.; Melkote, S., Ed.; Asian Media Information and Communication Centre: Singapore, 2012; pp. 199-217.

14. Hafkin, N. Women and gender in ICT statistics and indicators for development. Inf. Technol. Int. Dev. 2007, 4, 25-41.

15. Polat, R. Digital exclusion in Turkey: A policy perspective. Gov. Inf. Q. 2012, 29, 589-596. 
16. Pande, R. Gender gaps and information communication technology: A case study of India. In Globalization, Technology Diffusion, and Gender Disparity: Social Impacts of ICTs; Pande, R., van der Weide, T., Eds.; IGI Global: Hershey, PA, USA, 2012; pp. 277-291.

17. Melhem, S.; Morrell, C.; Tandon, N. Information Communication Technologies for women's Socioeconomic Empowerment. World Bank Working Paper 2009. Available online: http://elibrary.worldbank.org/doi/book/10.1596/978-0-8213-8133-5 (accessed on 3 August 2014).

18. Hafkin, N.; Huyer, S. Cinderella or Cyberella: Empowering women in the knowledge society. In Development in Practice; Kumarian Press: Bloomfield, CT, USA, 2007.

19. Moolman, J.; Primo, N.; Shackleton, S. Taking a byte of technology: Women and ICTs. Empower. Women Gend. Equity 2007, 21, 4-14.

20. Hafkin, N.; Taggart, N. Gender, IT and Developing Countries: An Analytic Study; Center for Education Innovations: Washington, DC, USA, 2001.

21. Dugdale, A. One fifth of women in the developing world think Internet use is inappropriate for them 2013. Available online: http://www.fastcompany.com/3004797/one-fifth-women-developingworld-countries-think-internet-use-inappropriate-them (accessed on 15 July 2014).

22. Weingarten, E. The Developing World Needs More Female Internet Users 2013. Available online: http://www.slate.com/articles/technology/technology/2013/01/a_new_report_on_female_internet_ users_from_the_developing_world.html (accessed on 21 July 2014).

23. Heavey, S. Women in India, Other Developing Countries Lag in Internet Use 2013. Available online: http://in.reuters.com/article/2013/01/10/internet-access-women-india-developingidINDEE90902820130110 (accessed on 2 August 2014).

24. Clauss, K.; Wakahiu, J.; Salvaterra, M. Using technology to educate women religious in Africa. Am. Int. J. Soc. Sci. 2013, 2, 29-37.

25. Gill, K.; Brooks, K.; McDougall, I.; Patel, P.; Kes, A. Bridging the Gender Divide: How Technology Can Advance Women Economically; International Centre for Research on Women: Washington, DC, USA, 2010.

26. Women and the Web. Intel 2013. Available online: http://www.intel.com/content/www/us/en/ technology-in-education/women-in-the-web.html (accessed on 1 July 2014).

27. Organisation for Economic Co-Operation and Development (OECD). Understanding the Digital Divide; OECD: Paris, France, 2001.

28. Global Media Monitoring Project (GMMP). Who Makes the News? 2010. Available online: http://www.genderlinks.org.za/article/who-makes-the-news-2010-global-media-monitoring-project2011-06-07 (accessed on 20 July 2014).

29. Hargiatti, E. The digital divide and what to do about it. In New Economy Handbook; Jones, D., Ed.; Academia Press: San Diego, CA, USA, 2003; pp. 821-839.

30. Liyanagunawardena, T.; Adams, A.; Rassool, N.; Williams, S. Using non-personal computers for e-Learning: Sri Lankan experience. J. Educ. Train. Stud. 2013, 1, 152-158.

31. Women's Annex Foundation. Available online: http://www.womensannexfoundation.org (accessed on 25 June 2014).

32. Strochlic, N. The Facebook Page Where Iran's Women Are Unveiling Online 2014. Available online: http://www.thedailybeast.com/articles/2014/05/18/the-facebook-page-where-iran-s-womenare-unveiling-online.html (accessed on 20 June 2014). 
33. World Bank. World Development Report: Attacking Poverty 2001. Available online: http:/www.ssc.wisc.edu/ walker/wp/wp-content/uploads/2012/10/wdr2001.pdf (accessed on 3 July 2014).

34. Tzannatos, Z. Women and labor market changes in the global economy: Growth helps, inequalities hurt and public policy matters. World Dev. 1999, 27, 551-569.

35. Vays, T. Women's Annex Foundation at NYC Bitcoin Centre: A Firsthand Look at Bitcoin Driving Positive Change in Afghanistan 2014. Available online: http://cointelegraph.com/news/112242/ womens-annex-foundation-nyc-bitcoin-center-a-firsthand-look-at-bitcoin-driving-positive-changein-afghanistan (accessed on 17 August 2014).

36. Educating Women and Girls in Developing Countries. Available online: http://newsroom. intel.com/community/intel_newsroom/blog/2013/09/30/intel-launches-she-will-connect-to-close-thetechnology-divide-for-millions-of-women-around-the-globe?author $=2014 / 08$ (accessed on 26 June 2014).

37. Improving Lives through Digital Literacy. Available online: http://www.intel.com/cd/corporate/ csr/apac/eng/news/news22/464790.htm (accessed on 23 July 2014).

(C) 2014 by the authors; licensee MDPI, Basel, Switzerland. This article is an open access article distributed under the terms and conditions of the Creative Commons Attribution license (http://creativecommons.org/licenses/by/4.0/). 